\title{
'||||||||||||||||||||||||||||||||||||||||||||||||||||||||||||||||||.
}

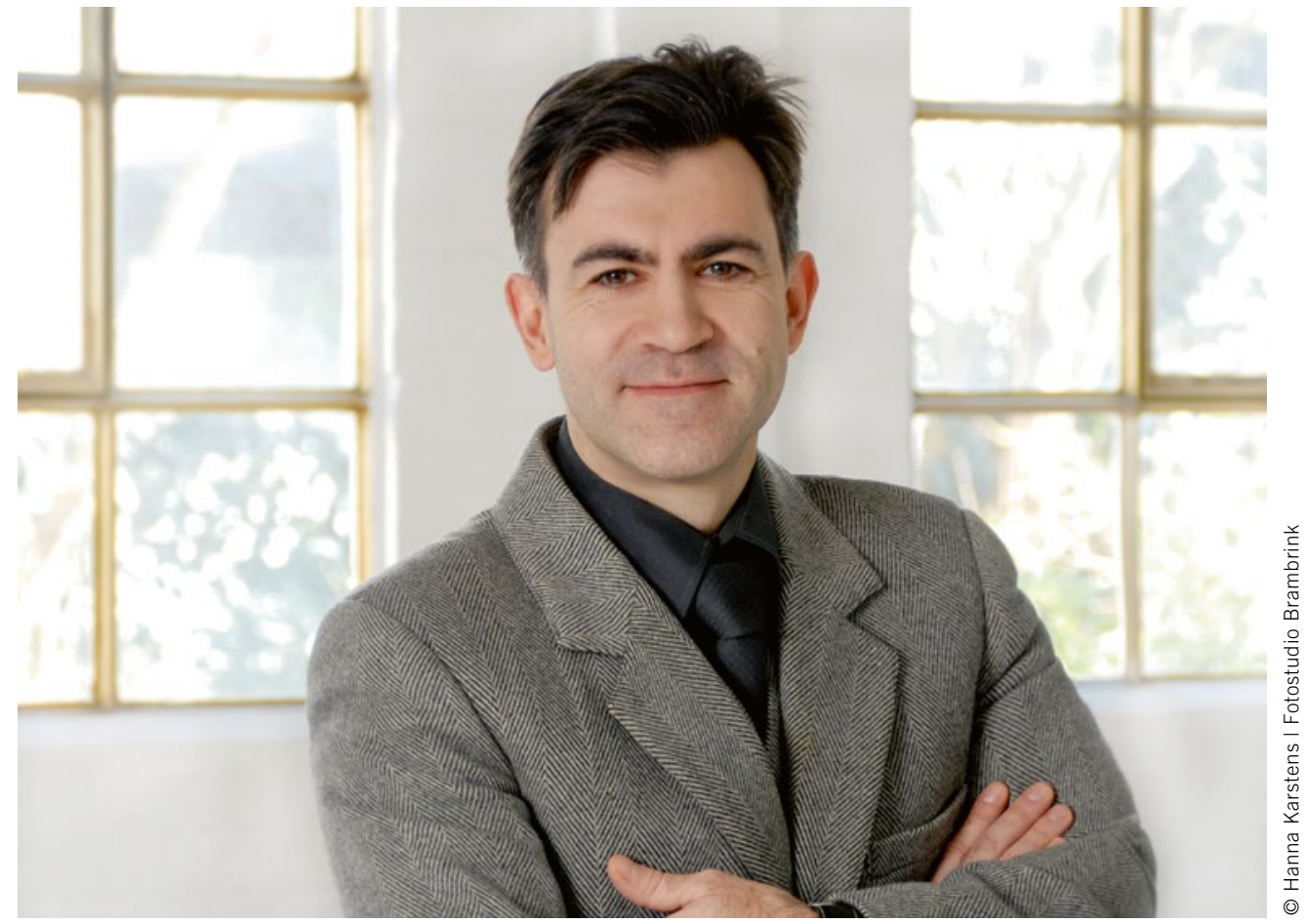

Prof. Alexander Piskun, M. Sc Professor of Body Design and Data Processing, Department of Automotive and Aeronautical Engineering, Faculty of Engineering and Computer Science, Hamburg University of Applied Sciences (Germany)

\section{The Challenges Facing Car Body Design}

We are living in turbulent times. Newspapers and magazines, which have dominated the scene in public transport for a century, are now gradually and almost imperceptibly being replaced by smartphones. One of the latest jokes is that the new basic requirements on the lower levels of Maslow's pyramid of human needs are a fully charged battery and a Wi-Fi connection.

The major changes that have recently taken place in vehicle design only become obvious at a second glance. Since the turn of the millennium, cars have been outfitted with beefy frontends, eye-catching front spoilers and higher bonnets, all of which were a concession to the new pedestrian protection regulations in force in Europe and Japan.

Electric powertrains are likely to have a greater impact on bodywork design. The Tesla Model X gives an indication of the direction that the body design of electric cars will take: Due to crash safety considerations, car batteries will increasingly be located under the vehicle's floor which puts the occupants in a higher sitting position, while the more compact drive systems free up additional space for the luggage compartment. The large number of derivatives is forcing car makers to develop platforms which reflect the new vehicle architecture. However, not only the car structure is affected: Among other changes electric drives may require different solutions for noise and heat insulation.

The exponential growth in technological innovations is being increasingly heavily influenced by developments in the fields of electronics and software. The cost-neutral doubling of the number of transistors in integrated circuit boards every two years, also known as Moore's Law, is driving the development of assistance systems and comfort functions. For example, it is expected that by 2018 we will see the mass production of highly integrated radar sensors the size of a matchbox. Positioned at the sides of a car, these sensors will be used to create a $360^{\circ}$ pre-crash sensor system that can also record and interpret the behaviour of pedestrians.

LED and laser technology is reducing the amount of space needed by headlight modules in the front-end and also allowing for extremely narrow headlight designs. The development of flexible OLED modules will pave the way to further improvements in rear light design on the one hand and more exclusive and integrated interior lighting on the other.

From an overall perspective, electronic systems are likely to have the greatest impact on road users over the next few years, while the changes to car bodies will play more of a background role. However, the many different activities involved in developing self-driving vehicles have the potential to turn our existing ideas about cars on their heads. The good thing here is that bodywork design has lost none of its fascination. In the light of this, I am looking forward to sharing ideas and experiences with you at the Hamburg Body Construction Conference on 3 and 4 May 2017. 